\title{
Whole-Body versus Local DXA-Scan for the Diagnosis of Osteoporosis in COPD Patients
}

\author{
Lidwien Graat-Verboom, ${ }^{1,2}$ Martijn A. Spruit, ${ }^{3}$ Ben E. E. M. van den Borne, ${ }^{2}$ \\ Frank W. J. M. Smeenk, ${ }^{2}$ and Emiel F. M. Wouters ${ }^{1,3}$ \\ ${ }^{1}$ Department of Respiratory Medicine, University Medical Centre Maastricht, P. Debyelaan 25, 6229 HX Maastricht, The Netherlands \\ ${ }^{2}$ Department of Respiratory Medicine, Catharina Hospital Eindhoven, Michelangelolaan 2, 5623 EJ Eindhoven, The Netherlands \\ ${ }^{3}$ Research, Development \& Education, CIRO, Centre of Expertise for Chronic Organ Failure, Hornerheide 1, \\ 6085 NM Horn, The Netherlands
}

Correspondence should be addressed to Lidwien Graat-Verboom, lidwiengraat@versatel.nl

Received 22 July 2009; Revised 21 October 2009; Accepted 2 January 2010

Academic Editor: David M. Reid

Copyright (C 2010 Lidwien Graat-Verboom et al. This is an open access article distributed under the Creative Commons Attribution License, which permits unrestricted use, distribution, and reproduction in any medium, provided the original work is properly cited.

\begin{abstract}
Background. Osteoporosis is an extrapulmonary effect of chronic obstructive pulmonary disease (COPD). Diagnosis of osteoporosis is based on BMD measured by DXA-scan. The best location for BMD measurement in COPD has not been determined. Aim of this study was to assess whole-body BMD and BMD of the hip and lumbar spine (local DXA) in COPD patients and compare the prevalence of osteoporosis at these locations. Methods. Whole body as well as local DXA-scan were made in 168 COPD patients entering pulmonary rehabilitation. Patient-relevant characteristics were assessed. Prevalence of osteoporosis was determined. Characteristics of patients without osteoporosis were compared to patients with osteoporosis on local DXA. Results. A higher prevalence of osteoporosis was found using local DXA compared to whole-body DXA (39\% versus 21\%). One quarter of patients without osteoporosis on whole body-DXA did have osteoporosis on local DXA. Significant differences in patient characteristics between patients without osteoporosis based on both DXA measurements and patients with osteoporosis based on local DXA only were found. Conclusions. DXA of the hip and lumbar spine should be made to assess bone mineral density in COPD patients. The lowest T-score of these locations should be used to diagnose osteoporosis.
\end{abstract}

\section{Introduction}

Chronic obstructive pulmonary disease (COPD) is characterized by a progressive airflow obstruction [1]. In addition, there are significant extrapulmonary effects, like osteoporosis. Osteoporosis is a systemic skeletal disease characterized by a low bone mineral density (BMD) and microarchitectural changes in bones leading to an increased bone fragility and, in turn, resulting in an increased fracture risk [2].

The prevalence of osteoporosis in COPD is higher than in healthy age-matched control subjects [3]. Moreover, COPD patients have a 60 to $70 \%$ higher risk of death following hip fracture than people without COPD [4]. It is therefore of high clinical importance to diagnose and treat osteoporosis in COPD according to international guidelines [2].
The gold standard for the diagnosis of osteoporosis is dual-energy absorptiometry (DXA) [2]. Multiple sites can be used to measure BMD by DXA. The sites most frequently used are the hip, the lumbar spine, forearm and/or whole-body. Several studies investigated the best location for DXA-scanning to diagnose osteoporosis [5-10]. DXAscanning of the hip and the lumbar spine resulted in a higher prevalence of osteoporosis than whole-body DXAscanning in pre- and postmenopausal women [6]. Indeed, the International Society for Clinical Densitometry advocates to measure BMD of the lumbar spine and the hip and to diagnose osteoporosis based on the lowest T-score of the measured locations [11]. To date, a comparison of BMD of various skeletal sites has not been performed in patients with clinically stable COPD. Therefore, the aim of this study was to compare the prevalence of osteoporosis using whole-body 
TABle 1: Patients characteristics.

\begin{tabular}{|c|c|c|c|c|}
\hline & Total group $(N=168)$ & $\operatorname{Men}(N=103)$ & Women $(N=65)$ & $P$-value \\
\hline Age, years & $63.6 \pm 9.1(39-85)$ & $65.9 \pm 8.6$ & $60.0 \pm 8.7$ & $<.001$ \\
\hline FEV1, \%predicted & $44.3 \pm 18.5$ & $45.06 \pm 18.1$ & $43.12 \pm 19.2$ & .0510 \\
\hline GOLD I, \% & 6.0 & 6.8 & 4.6 & \multirow{4}{*}{.402} \\
\hline GOLD II, \% & 24.6 & 24.3 & 26.2 & \\
\hline GOLD III, \% & 26.3 & 30.1 & 20.0 & \\
\hline GOLD IV, \% & 43.1 & 38.8 & 49.2 & \\
\hline \multicolumn{5}{|l|}{ Arterial blood gas } \\
\hline $\mathrm{pH}$ & $7.43 \pm 0.03$ & $7.44 \pm 0.03$ & $7.43 \pm 0.03$ & .078 \\
\hline $\mathrm{PaCO}_{2}, \mathrm{kPa}$ & $5.4 \pm 0.8$ & $5.4 \pm 0.9$ & $5.6 \pm 0.7$ & .106 \\
\hline $\mathrm{PaO}_{2}, \mathrm{kPa}$ & $9.5 \pm 1.4$ & $9.5 \pm 1.5$ & $9.4 \pm 1.3$ & .466 \\
\hline $\mathrm{SO}_{2}, \%$ & $95 \pm 3$ & $94 \pm 3$ & $95 \pm 2$ & .536 \\
\hline \multicolumn{5}{|l|}{ Smoking } \\
\hline Ex-Smoker*, \% & 66.7 & 71.8 & 58.5 & .073 \\
\hline Pack Years & $38.8 \pm 15.5$ & $38.9 \pm 15.0$ & $38.8 \pm 1603$ & .960 \\
\hline BMI, kg/m² & $24.7 \pm 4.4$ & $24.7 \pm 4.4$ & $24.7 \pm 4.5$ & .960 \\
\hline Low, \% & 20.8 & 21.4 & 20.0 & \multirow{4}{*}{.561} \\
\hline Normal, \% & 30.4 & 33.0 & 26.2 & \\
\hline High, \% & 38.1 & 34.0 & 44.6 & \\
\hline Obese, \% & 10.7 & 11.7 & 9.2 & \\
\hline FFMI, kg/m² & $16.1 \pm 2.1$ & $16.8 \pm 2.0$ & $15.1 \pm 1.8$ & $<.001$ \\
\hline Normal/Low, \% & $58.9 / 41.1$ & $61.2 / 38.8$ & $55.4 / 44.6$ & .458 \\
\hline \multicolumn{5}{|l|}{ Whole body DXA } \\
\hline $\mathrm{BMD}, \mathrm{g} / \mathrm{cm}^{2}$ & $1.079 \pm 0.118$ & $1.113 \pm 0.114$ & $1.025 \pm 0.103$ & $<.001$ \\
\hline T-score & $-1.3 \pm 1.4$ & $-1.3 \pm 1.4$ & $-1.3 \pm 1.3$ & .762 \\
\hline Normal BMD, \% & 40.5 & 41.7 & 38.5 & .075 \\
\hline Osteopenia, \% & 36.9 & 31.1 & 46.2 & .217 \\
\hline Osteoporosis, \% & 22.6 & 27.2 & 15.4 & .081 \\
\hline \multicolumn{5}{|l|}{ DXA hip } \\
\hline $\mathrm{BMD}, \mathrm{g} / \mathrm{cm}^{2}$ & $0.827 \pm 0.149$ & $0.858 \pm 0.146$ & $0.779 \pm 0.143$ & .001 \\
\hline T-score & $-1.7 \pm 1.1$ & $-1.6 \pm 1.1$ & $-1.9 \pm 1.0$ & .151 \\
\hline Normal BMD, \% & 22.6 & 25.2 & 18.5 & \\
\hline Osteopenia, \% & 52.4 & 53.4 & 52.3 & .400 \\
\hline Osteoporosis, \% & 25.0 & 21.4 & 29.2 & \\
\hline \multicolumn{5}{|l|}{ DXA LS } \\
\hline $\mathrm{BMD}, \mathrm{g} / \mathrm{cm}^{2}$ & $1.065 \pm 0.215$ & $1.088 \pm 0.211$ & $1.027 \pm 0.218$ & .074 \\
\hline T-score & $-1.3 \pm 1.8$ & $-1.2 \pm 1.8$ & $-1.4 \pm 1.8$ & .471 \\
\hline Normal BMD, \% & 39.3 & 44.7 & 30.8 & .198 \\
\hline Osteopenia, \% & 33.3 & 30.1 & 38.5 & \\
\hline Osteoporosis, \% & 27.4 & 25.2 & 30.8 & \\
\hline \multicolumn{5}{|l|}{ DXA hip and LS } \\
\hline Normal BMD, \% & 15.5 & 19.4 & 10.8 & \multirow{3}{*}{.175} \\
\hline Osteopenia, \% & 45.8 & 46.6 & 43.1 & \\
\hline Osteoporosis, \% & 38.7 & 34.0 & 46.2 & \\
\hline $6 \mathrm{MWD}, \mathrm{m}(n=165)$ & $420.61 \pm 135.66$ & $454.41 \pm 132.57$ & $368.62 \pm 124.28$ & $<.001$ \\
\hline Oral corticosteroids, \% & 17,9 & 18.4 & 16.9 & .802 \\
\hline Daily dose ${ }^{\#}, \mathrm{mg}$ & $5.9 \pm 2.1(2.5-10)$ & $6.1 \pm 2.1$ & $5.7 \pm 2.3$ & .653 \\
\hline $\begin{array}{l}\text { Inhaled } \\
\text { corticosteroids, \% }\end{array}$ & $85.7 \%$ & 83.5 & 89.2 & .301 \\
\hline
\end{tabular}

Results are presented as means \pm standard deviation, unless otherwise indicated.

* Rest of the patients are current smokers.

\# Only patients using oral corticosteroids on a daily base $(n=30)$.

Abbreviations: $\mathrm{FEV} 1$ = forced expiratory volume in the first second; GOLD = Global Strategy for the Diagnosis, Management and prevention of COPD; COPD $=$ chronic obstructive pulmonary disease; $\mathrm{BMI}=$ body mass index; FFMI $=$ fat free mass index; $\mathrm{DXA}=$ dual energy absorptiometry; $\mathrm{BMD}=$ bone mineral density; $\mathrm{LS}=$ lumbar spine; $6 \mathrm{MWD}=$ six minutes walking distance; $\mathrm{m}=$ meters; $\mathrm{PaCO}_{2}=$ arterial carbon dioxide tension; $\mathrm{PaO}_{2}=\mathrm{Arterial}_{\text {oxygen tension; }}$ $\mathrm{SO}_{2}=$ Oxygen saturation. 
TABLE 2: Osteoporosis versus no osteoporosis based on local DXA and whole body DXA.

\begin{tabular}{lcc}
\hline \multirow{2}{*}{ Whole body DXA } & \multicolumn{2}{c}{ Local DXA } \\
& Osteoporosis & No osteoporosis \\
\hline Osteoporosis & 33 & 5 \\
No osteoporosis & 32 & 98 \\
\hline
\end{tabular}

Post Hoc test (McNemar): Relative risk 6.4; 95\% confidence interval 2.9332.06; $P<.0001$. (Relative risk: the risk of having osteoporosis on local DXA in case of a normal whole-body DXA is 6.4 times higher than the risk of having osteoporosis on whole body DXA in case of a normal local DXA.)

TABle 3: Osteoporosis versus no osteoporosis based on DXA of the lumbar spine and of the hip.

\begin{tabular}{lcc}
\hline \multirow{2}{*}{ DXA Hip } & \multicolumn{2}{c}{ DXA LS } \\
\hline Osteoporosis & Osteoporosis & No osteoporosis \\
No osteoporosis & 23 & 19 \\
\hline
\end{tabular}

Abbreviations: $\mathrm{LS}=$ lumbar spine.

Post hoc test (McNemar): Relative risk 1.21; $P=.644$. (Relative risk: the risk of having osteoporosis on lumbar spine DXA in case of a normal hip DXA is 1.21 times higher than the risk of having osteoporosis on hip DXA in case of a normal lumbar spine DXA.)

DXA-scanning versus local DXA-scanning (hip and lumbar spine) in male and female COPD patients. To identify risk factors for osteoporosis, patients without osteoporosis based on both DXA measurements were compared to patients with osteoporosis based on local DXA only.

\section{Methods}

The results of 168 consecutive COPD patients between November 2007 and May 2008 at CIRO, a centre of expertise for chronic organ failure in Horn (the Netherlands), were included in this retrospective study. All patients underwent all the tests during a 3-day baseline assessment before entering a patient-tailored pulmonary rehabilitation program [12]. Therefore, our manuscript does not include a statement of patient consent and the approval of Internal Review Boards.

Medical history, current medication use, and smoking status were assessed. Post-bronchodilator pulmonary function tests were performed (Jaeger MASTERLABBODY, VIASYS Healthcare) and COPD was diagnosed and classified according to the GOLD guidelines [1]. Body mass index (BMI) was defined as low $\left(<21 \mathrm{~kg} / \mathrm{m}^{2}\right)$, normal $\left(21-25 \mathrm{~kg} / \mathrm{m}^{2}\right)$, overweight $\left(>25-30 \mathrm{~kg} / \mathrm{m}^{2}\right)$, and obese $\left(>30 \mathrm{~kg} / \mathrm{m}^{2}\right)$. Fat-free mass index (FFMI) was assessed by bio-impedance analysis (BODYSTAT 1500 medical, single frequency; Xitron Technologies) and classified as depleted (men $<16 \mathrm{~kg} / \mathrm{m}^{2}$ and women $<15 \mathrm{~kg} / \mathrm{m}^{2}$ ) or normal [13]. A six-minute walking distance test was performed to estimate functional exercise capacity [14]. Arterial blood gases were collected to determine $\mathrm{pH}$, arterial carbon dioxide tension $\left(\mathrm{PaCO}_{2}\right)$, and arterial oxygen tension $\left(\mathrm{PaO}_{2}\right)$.
Whole-body BMD as well as BMD at the femur and the lumbar spine (L1-L4) were assessed for each patient using a DXA-scan (Lunar Prodigy Ge-Lunar). Because the risk of hip and vertebral fractures is similar in men and women for any given BMD, we used the NHANES III data to calculate T-scores for both men and women $[15,16]$. For wholebody DXA osteoporosis was defined by a T-score $<-2.35$, osteopenia: T-score between -2.35 and -0.9 , and normal BMD: T-score $>-0.9$ [17]. For local DXA, osteoporosis was defined by a T-score of $\leq-2.5$, osteopenia as T-score between -1 and -2.5 , and normal BMD: T-score $>-1$ [2]. To compare different locations of DXA-scan, we divided groups into osteoporosis and no osteoporosis (osteopenia and normal BMD combined) because only patients with osteoporosis need to be treated pharmacologically.

2.1. Statistical Analyses. Discrete variables were compared with the Chi-square test and presented as percentages. Continuous variables were compared with independent $t$ test and presented as means \pm standard deviation (SD). Pearson correlation was used. To estimate the relative risk a McNemars test was used. A $P$-value of $<.05$ was considered significant. All statistical analyses were performed using Statistical Package for Social Sciences (SPSS) version 16.0.

\section{Results}

Mostly male patients with clinically stable, mild to very severe COPD were studied. Based on whole-body DXA-scan prevalence of osteoporosis was $22.6 \%$ versus $38.7 \%$ based on hip and/or the lumbar spine DXA-scan (local DXA) (Table 1).

Twenty-five percent of the 130 patients with a T-score $>-2.35$ as determined by whole-body DXA did have osteoporosis based on local DXA. In contrast, only 3.7\% of the 103 patients with a T-score $>-2.5$ as determined by local DXA did have osteoporosis based on whole-body DXA (Table 2). This difference in prevalence was highly significant $(P<.0001)$. The relative risk of having osteoporosis on local DXA in case of no osteoporosis on whole-body DXA was 6.4 times higher than the risk of having osteoporosis on wholebody DXA in case of no osteoporosis on local DXA (Table 2).

Almost $16 \%$ of 122 patients with T-scores $>-2.5$ as determined by DXA at the lumbar spine did have osteoporosis based on DXA at the hip. In addition, a little over $18 \%$ of 126 patients with T-scores $>-2.5$ based on hip DXA-scanning did have osteoporosis on DXA-scan of the lumbar spine (Table 3). This difference was not significant $(P=.644)$.

Significant differences were found in genderdistribution, proportion of GOLD IV patients, arterial blood gases, and functional exercise capacity between COPD patients without osteoporosis on whole-body DXA as well as local (hip and lumbar spine) DXA (group I) and those without osteoporosis on whole body DXA and with osteoporosis on local DXA (group II) (Table 4). 
TABLE 4: Differences between patients without osteoporosis and osteoporosis on local DXA.

\begin{tabular}{|c|c|c|c|}
\hline & Group I $(N=98)$ & Group II $(N=32)$ & $P$-value \\
\hline Male/Female, \% & $64 / 36$ & $38 / 62$ & .008 \\
\hline Age, years & $64.0 \pm 9.2$ & $61.7 \pm 9.2$ & .229 \\
\hline FEV1, \% predicted & $46.6 \pm 17.3$ & $40.7 \pm 20.9$ & .110 \\
\hline GOLD I, \% & 5 & 6 & .803 \\
\hline GOLD II, \% & 29 & 19 & .272 \\
\hline GOLD III, \% & 31 & 16 & .097 \\
\hline GOLD IV, \% & 36 & 59 & .018 \\
\hline \multicolumn{4}{|l|}{ Arterial blood gas } \\
\hline $\mathrm{pH}$ & $7.43 \pm 0.03$ & $7.42 \pm 0.03$ & .267 \\
\hline $\mathrm{PaCO}_{2}(\mathrm{kPa})$ & $5.38 \pm 0.72$ & $5.71 \pm 0.85$ & .033 \\
\hline $\mathrm{PaO}_{2}(\mathrm{kPa})$ & $9.62 \pm 1.28$ & $9.00 \pm 1.51$ & .024 \\
\hline $\mathrm{SO}_{2}(\%)$ & $94.91 \pm 2.54$ & $93.73 \pm 3.03$ & .032 \\
\hline BMI & $25.88 \pm 3.93$ & $25.11 \pm 4.03$ & .342 \\
\hline Low BMI, \% & 8 & 19 & .093 \\
\hline Normal BMI, \% & 35 & 25 & .309 \\
\hline High BMI, \% & 43 & 47 & .691 \\
\hline Obese BMI, \% & 14 & 9 & .474 \\
\hline 6MWD, meters & $443 \pm 128$ & $354 \pm 146$ & .002 \\
\hline
\end{tabular}

Group I = Patients without osteoporosis on total body DXA-scan and without osteoporosis on local DXA-scan.

Group II = Patients without osteoporosis on total body DXA-scan and with osteoporosis on local DXA-scan.

Results are presented as mean \pm standard deviation or as $\%$ of the group.

Abbreviations: FEV1 = forced vital capacity in the first second; GOLD = Global Strategy for the Diagnosis, Management and prevention of COPD; COPD $=$ chronic obstructive pulmonary disease; $\mathrm{PaCO}_{2}=$ arterial blood carbon dioxide tension; $\mathrm{PaO}_{2}=$ arterial blood oxygen tension; $\mathrm{SO} \mathrm{O}_{2}=$ oxygen saturation in arterial blood; $\mathrm{BMI}=$ body mass index. $6 \mathrm{MWD}=6$ minutes walking distance.

\section{Discussion}

Appreciating the possible impact of osteoporosis on fractures and survival in COPD [4], it is clinically important to have an early and accurate diagnosis. In the present study a methodspecific difference in diagnosing osteoporosis has been found in patients with COPD. Indeed, whole-body DXA-scanning underestimates the prevalence of osteoporosis in COPD (Table 1). This finding is in accordance with the findings in pre- and postmenopausal women without COPD [6].

The prevalence of osteoporosis has been shown to differ when the same cut-off value for the T-score is used to define osteoporosis $[18,19]$. This leads to an over- or underestimation of osteoporosis depending on the method used to asses $\mathrm{BMD}$. In order to compare whole-body DXA to local DXA, we corrected for this difference in methodology by defining osteoporosis according to Boyanov [17] and the WHO [2], respectively. In turn, a good sensitivity-to-specificity ratio in the diagnosis of osteoporosis was obtained [17].

A possible explanation for the method-specific differences in prevalence of osteoporosis may be age-related. Indeed, loss of BMD of the lumbar spine occurs at a younger age than loss of BMD of the hip $[6,20]$. In addition, due to degenerative changes of the spine at higher age, lumbar BMD could even be increased in the elderly. In the present trial the prevalence of osteoporosis was slightly higher using lumbar spine DXA (27.4\%) compared to hip DXA (25.0\%), while the prevalence of osteopenia was clearly higher in the latter group (33.3\% versus $52.4 \%$ ). Consequently, these patients may be at risk to develop osteoporosis.
The International Society for Clinical Densitometry stated that the BMD of the spine and the hip should be measured and diagnosis of osteoporosis should be based on the lowest T-score of either the spine or the hip [11]. Indeed, in our COPD patients we found the prevalence of osteoporosis based on DXA of the hip to be $25 \%$, of the lumbar spine $27.4 \%$, and of the hip and lumbar spine combined $38.7 \%$ (Table 1). In combination with the fact that $25 \%$ of patients without osteoporosis on whole-body DXA had osteoporosis on local DXA, it seems reasonable to advise DXA of the hip and the lumbar spine and diagnose osteoporosis based on the lowest T-score in COPD patients. The costs of a whole-body DXA are the same as a local DXA scan. In addition, the costs of a DXA of the hip or the lumbar spine only are equal to the costs of a DXA scan of both the hip and lumbar spine. Therefore, there are no economical reasons to limit DXA-scan to the hip only. In addition, the time to make a local DXA scan is less than the time to make a whole body DXA. More research is needed to assess risk factors for osteoporosis in COPD in order to determine which patients should be evaluated for osteoporosis.

The current study showed that the group of patients without osteoporosis on whole-body DXA but with osteoporosis on local DXA consisted of significantly more females than males, patients with a lower six minutes walking distance and more patients with GOLD IV and higher $\mathrm{PaCO}_{2}$ and lower $\mathrm{PaO}_{2}$ levels as compared to patients without osteoporosis on both whole body- and local DXA (Table 4). Therefore, in this group of patients, it seems even more important to use local DXA to determine BMD instead 
of whole-body DXA. Even more because in the general population the fracture risk is increased in females [21] and in COPD patients, a higher prevalence of osteoporosis has been found in patients with higher GOLD classification and/or hypercapnic patients [22-26]. In the current study, the increased number of patients with GOLD IV COPD in group II is probably not due to increased airway obstruction (FEV1 was not significantly different in both groups), but to hypercapnia and/or hypoxemia (Table 4). Indeed, Dimai and colleagues found a significantly lower BMD and increased serum cross-linked telopeptide of type I collagen (a bone resorption marker) in hypercapnic patients suggesting that hypercapnia induces increased bone resorption [23]. With decreased daily physical activity, hip BMD especially will be decreased, which will be compensated by the BMD of other non-weight baring body parts when whole body BMD is assessed.

When results of whole body DXA-scanning were added to local DXA-scanning, only 5 extra patients without osteoporosis on local DXA had a T-score of $<-2.35$ on the whole body DXA-scan (2.4\%).

To conclude, in future COPD trials, in which the diagnosis and/or treatment of osteoporosis is a primary outcome measure and in daily clinical practice, the most sensitive procedure for diagnosing osteoporosis should be used. On the basis of our findings, we advise to assess the BMD at the hip and lumbar spine and finally take the lowest T-score of these 2 locations to determine the prevalence of osteoporosis.

\section{Acknowledgments}

The authors are grateful to Trineke Hofstra en Ans Suntjens for the careful determination of bone mineral density at CIRO in Horn, the Netherlands. They thank Wilco Emons, department of Methodology and Statistics, Tilburg University, the Netherlands for his statistical advises.

\section{References}

[1] K. F. Rabe, S. Hurd, A. Anzueto, et al., "Global strategy for the diagnosis, management, and prevention of chronic obstructive pulmonary disease: GOLD executive summary," American Journal of Respiratory and Critical Care Medicine, vol. 176, no. 6, pp. 532-555, 2007.

[2] WHO Scientific Group on the Prevention and Management of Osteoporosis, "Prevention and management of osteoporosis: report of a WHO scientific group," Internet Communication, 2007.

[3] L. Graat-Verboom, E. F. M. Wouters, F. W. J. M. Smeen, B. E. E. M. van den Borne, R. Lunde, and M. A. Spruit, "Current status of research on osteoporosis in COPD: a systematic review," European Respiratory Journal, vol. 34, no. 1, pp. 209-218, 2009.

[4] C. de Luise, M. Brimacombe, L. Pedersen, and H. T. Sorensen, "Chronic obstructive pulmonary disease and mortality following hip fracture: a population-based cohort study," European Journal of Epidemiology, vol. 23, no. 2, pp. 115-122, 2008.

[5] A. Arabi, R. Baddoura, H. Awada, et al., "Discriminative ability of dual-energy X-ray absorptiometry site selection in identifying patients with osteoporotic fractures," Bone, vol. 40, no. 4, pp. 1060-1065, 2007.

[6] M. E. Arlot, E. Sornay-Rendu, P. Garnero, B. Vey-Marty, and P. D. Delmas, "Apparent pre- and postmenopausal bone loss evaluated by DXA at different skeletal sites in women: the OFELY cohort," Journal of Bone and Mineral Research, vol. 12, no. 4, pp. 683-690, 1997.

[7] H. Franck and M. Munz, "Total body and regional bone mineral densitometry (BMD) and soft tissue measurements: correlations of BMD parameter to lumbar spine and hip," Calcified Tissue International, vol. 67, no. 2, pp. 111-115, 2000.

[8] W. D. Leslie, J. F. Tsang, P. A. Caetano, and L. M. Lix, "Number of osteoporotic sites and fracture risk assessment: a cohort study from the Manitoba Bone Density Program," Journal of Bone and Mineral Research, vol. 22, no. 3, pp. 476-483, 2007.

[9] D. A. Nelson, R. Molloy, and M. Kleerekoper, "Prevalence of osteoporosis in women referred for bone density testing: utility of multiple skeletal sites," Journal of Clinical Densitometry, vol. 1, no. 1, pp. 5-11, 1998.

[10] S. M. Nickols-Richardson, L. E. Miller, D. F. Wootten, et al., "Distal tibia areal bone mineral density: use in detecting low aBMD of the hip in young women," Journal of Clinical Densitometry, vol. 8, no. 1, pp. 74-79, 2005.

[11] "2007 official positions of The International Society For Clinical Densitometry," Internet Communication, 2008.

[12] M. A. Spruit, I. Vanderhoven-Augustin, P. P. Janssen, and E. F. Wouters, "Integration of pulmonary rehabilitation in COPD," The Lancet, vol. 371, no. 9606, pp. 12-13, 2008.

[13] A. M. W. J. Schols, P. B. Soeters, A. M. C. Dingemans, R. Mostert, P. J. Frantzen, and E. F. M. Wouters, "Prevalence and characteristics of nutritional depletion in patients with stable COPD eligible for pulmonary rehabilitation," American Review of Respiratory Disease, vol. 147, no. 5, pp. 1151-1156, 1993.

[14] F. Pitta, T. Troosters, M. A. Spruit, V. S. Probst, M. Decramer, and R. Gosselink, "Characteristics of physical activities in daily life in chronic obstructive pulmonary disease," American Journal of Respiratory and Critical Care Medicine, vol. 171, no. 9, pp. 972-977, 2005.

[15] A. C. Looker, E. S. Orwoll, C. C. Johnston Jr., et al., "Prevalence of low femoral bone density in older U.S. adults from NHANES III," Journal of Bone and Mineral Research, vol. 12, no. 11, pp. 1761-1768, 1997.

[16] A. C. Looker, H. W. Wahner, W. L. Dunn, et al., "Updated data on proximal femur bone mineral levels of US adults," Osteoporosis International, vol. 8, no. 5, pp. 468-489, 1998.

[17] M. Boyanov, "Estimation of lumbar spine bone mineral density by dual-energy X-ray absorptiometry: standard anteroposterior scans vs sub-regional analyses of whole-body scans," British Journal of Radiology, vol. 81, no. 968, pp. 637-642, 2008.

[18] K. G. Faulkner, E. von Stetten, and P. Miller, "Discordance in patient classification using T-scores," Journal of Clinical Densitometry, vol. 2, no. 3, pp. 343-350, 1999.

[19] Y. Lu, H. K. Genant, J. Shepherd, et al., "Classification of osteoporosis based on bone mineral densities," Journal of Bone and Mineral Research, vol. 16, no. 5, pp. 901-910, 2001.

[20] A. Blumsohn and R. Eastell, Osteoporosis: Etiology, Diagnosis, and Management, Lippincott-Raven, Philadelphia, Pa, USA, 2nd edition, 1995.

[21] J. A. Kanis, O. Johnell, A. Oden, H. Johansson, and E. McCloskey, "FRAX and the assessment of fracture probability in men and women from the UK," Osteoporosis International, vol. 19, no. 4, pp. 385-397, 2008. 
[22] D. D. Bikle, B. Halloran, L. Fong, L. Steinbach, and J. Shellito, "Elevated 1,25-dihydroxyvitamin D levels in patients with chronic obstructive pulmonary disease treated with prednisone," Journal of Clinical Endocrinology and Metabolism, vol. 76, no. 2, pp. 456-461, 1993.

[23] H. P. Dimai, W. Domej, G. Leb, and K.-H. W. Lau, "Bone loss in patients with untreated chronic obstructive pulmonary disease is mediated by an increase in bone resorption associated with hypercapnia," Journal of Bone and Mineral Research, vol. 16, no. 11, pp. 2132-2141, 2001.

[24] A. Kjensli, P. Mowinckel, M. S. Ryg, and J. A. Falch, "Low bone mineral density is related to severity of chronic obstructive pulmonary disease," Bone, vol. 40, no. 2, pp. 493-497, 2007.

[25] T. C. Mineo, V. Ambrogi, D. Mineo, A. Fabbri, E. Fabbrini, and R. Massoud, "Bone mineral density improvement after lung volume reduction surgery for severe emphysema," Chest, vol. 127, no. 6, pp. 1960-1966, 2005.

[26] A. Vrieze, M. H. G. De Greef, P. J. Wijkstra, and J. B. Wempe, "Low bone mineral density in COPD patients related to worse lung function, low weight and decreased fat-free mass," Osteoporosis International, vol. 18, no. 9, pp. 1197-1202, 2007. 


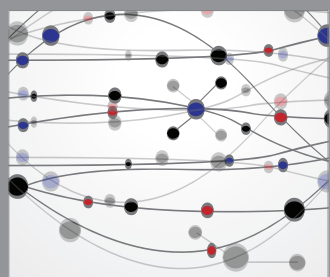

The Scientific World Journal
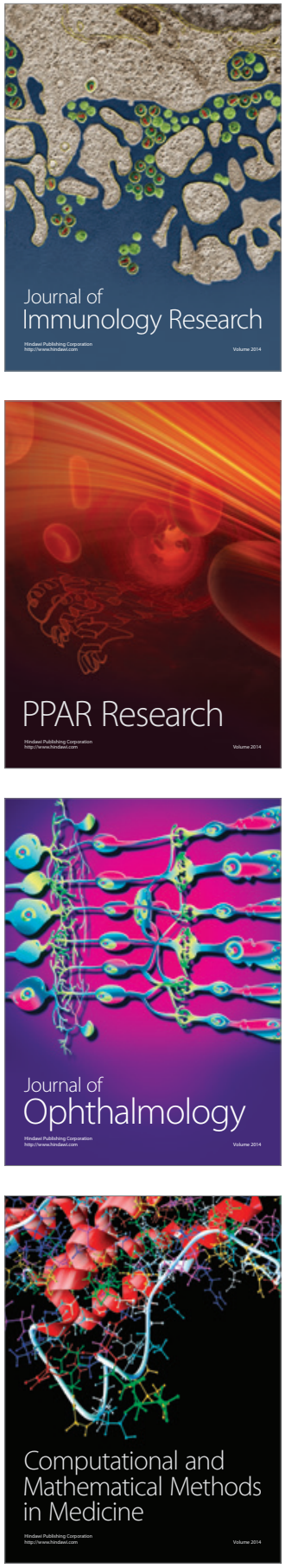

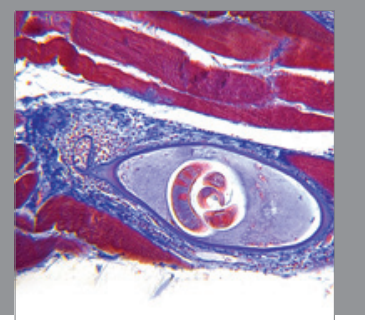

Gastroenterology

Research and Practice
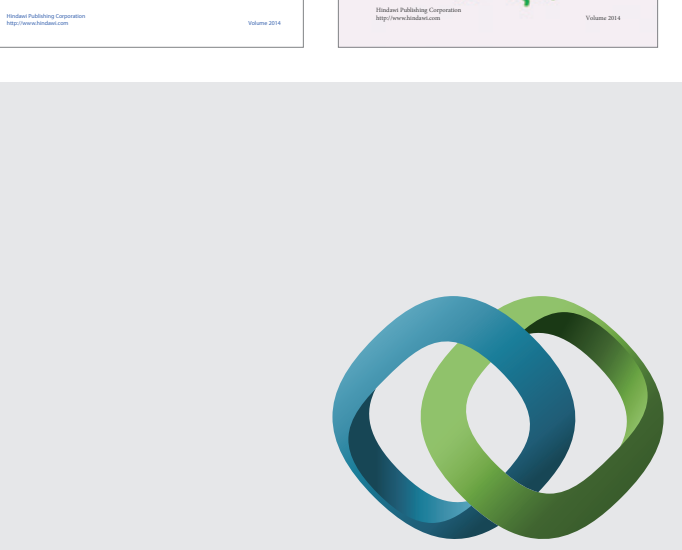

\section{Hindawi}

Submit your manuscripts at

http://www.hindawi.com
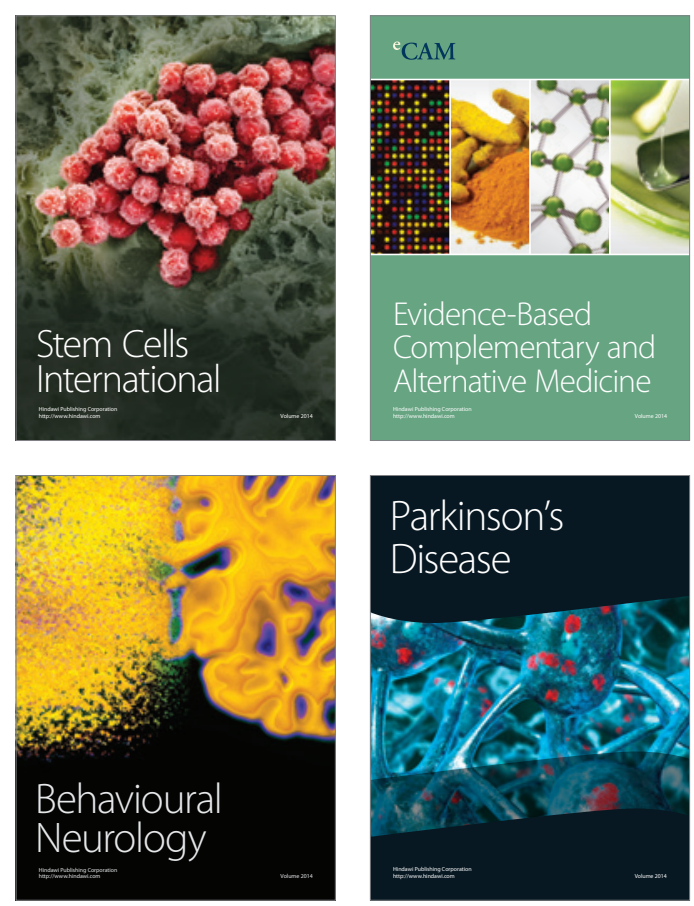

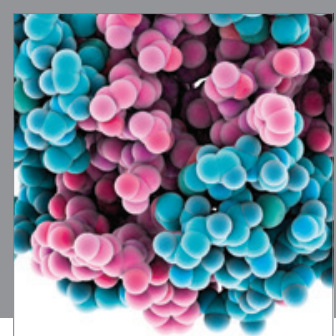

Journal of
Diabetes Research

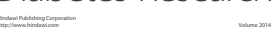

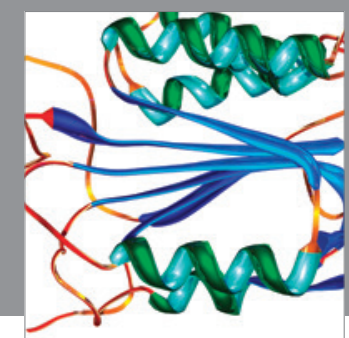

Disease Markers
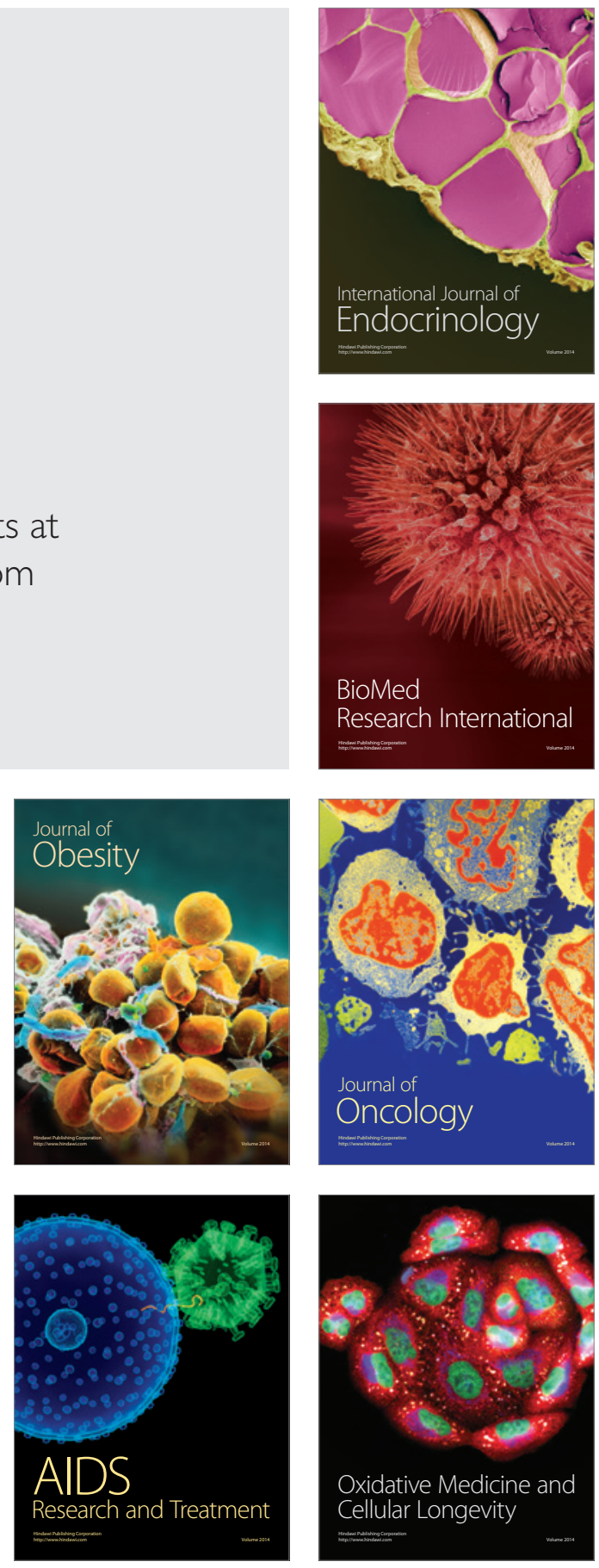